\title{
Accommodating (to) ELF in the international university
}

\author{
Jennifer Jenkins \\ Modern Languages, Faculty of Humanities, University of Southampton SO17 1BJ
}

\begin{abstract}
This article takes as its starting point the fact that the majority of universities in which English is the medium of instruction perceive themselves to be deeply international. Firstly, the article considers the implications of being 'international' for academic language policies and practices, but observes that despite the diverse international composition of university student (and to a lesser extent, staff) populations, university language policies and practices are still grounded in largely national (British and North American) English norms. The article goes on to explore the relevance of the findings of research into English as a(n academic) lingua franca for multilingual academic communities, as well as for international academic journals. Finally, it considers the implications of ELF research for native English academics, and argues that as ELF gains acceptance, particularly among younger multilingual speakers, and as multilingualism becomes the global academic norm, native English speakers, especially the monolingual majority, are at risk of becoming disadvantaged when communicating in international settings.
\end{abstract}

Keywords: Academic ELF; Accommodation; Code-switching; English language policy

\section{Introduction}

During the past few decades, English has become the dominant global lingua franca, and this is having a major impact on the way the language is used. For, as Graddol (2006:11) points out, it is no longer "English as we have known it, and have taught it in the past as a foreign language" but "a new phenomenon": in other words, English as a Lingua Franca, or ELF as it is generally known for short. However, while plentiful research demonstrates that ELF has emerged in practice as a different kind of English from that used by native English speakers among themselves and traditionally taught to foreign learners, it is still regarded by many, even some sociolinguists, as an inferior kind of English. Not surprisingly, then, native (essentially British or American) English is still widely considered to be the most desirable kind of English, and remains the version of the language taught to non-native English speakers around the world, i.e. English as a Foreign Language (EFL). In taking scant account of the massive spread of English, the unprecedented amount of language contact involved, and the effects of this contact on the international use of English, English language policy thus lags far

- Tel.: +23 8059 7046, fax: +23 80593288

E-mail address: J.Jenkins@soton.ac.uk 
behind English language practice. And this is particularly true of academic English settings.

Many of the world's universities especially but not exclusively in Europe (including the UK) and Asia, consider themselves to be deeply international, often proclaiming their international/global 'credentials' in their promotional literature. This is undoubtedly the case as far as their multi-national student intake is concerned, an intake that has both led to and resulted from the rapid rise in the use of English as the main or only medium of instruction in tertiary education. The increase in English medium universities and their multi-lingual, multi-cultural student (and, to a lesser extent, staff) membership means that universities represent settings par excellence of English as a(n academic) lingua franca. Added to this is the fact that most international academic conferences, seminars, workshops and the like, regardless of their geographical setting, are conducted using English as their main, and usually only, lingua franca, even though there are often few or no native English speakers present. Meanwhile, the vast majority of academic journals with international distributions remain deeply grounded in the norms of British and/or North American academic English, despite their (linguistically paradoxical) claims to internationalism.

While one might expect academia as a whole, and universities, with their substantial international communities, in particular, to be revisiting their English language policies, this seems not to be happening outside a relatively small group of researchers into academic ELF. Instead, it is largely 'business as usual', with the focus remaining on helping students in dedicated pre- and in-sessional classes to improve their English in line with the norms of standard British or American academic English, both spoken and written. At its best, the current situation may result in individual university lecturers unilaterally accepting, if not condoning, instances of English that diverge mildly from standard native use but are nevertheless intelligible to them. On the other hand, at its worst, the situation leads to assumptions that any such divergences are errors in need of remediation, and even on occasion to ranting caricatures of non-native academic English, such as the following:

How can anyone learn a hotchpotch in which it does not matter how the words are spelt, whether or not singulars are distinguished from plurals, and which syllables are stressed in speech and which are not? Chinglish, Singlish, or Schminglish: take your choice.

(Harris, 2007; emphasis added).

Yet, as will be discussed below, the features caricatured by Harris are among those that have been found in empirical research to be used systematically and effectively by highly proficient ELF speakers.

The status quo also means that international university English language requirements continue to be determined in accordance with entrance examinations grounded in native English, in other words, a national variety. Indeed, it seems that examination boards interpret the concept of 'international' as the international distribution of native English (see Widdowson 1997 on the distinction between the distribution and spread of English). A representative of the new Pearson Test of English (PTE) Academic, for example, stated in an interview with the periodical, $E L$ Gazette (September 2008:10), that "to create an international exam we started by hiring item writers from the UK, the US and Australia", and added "[b]ecause we are not using a single standard model of English, we can grade all non-native students on a single scale. The first thing we look for is comprehensibility - are they understandable to the native speaker?". Inevitably this kind of approach - and the other main 'international' examinations such as IELTS and TOEFL are no different in this respect 
- continues to spawn a stream of course books with titles such as Common mistakes at IELTS Advanced and how to avoid them (Moore, 2007) that provide prospective candidates with advice on how to make their English not only understandable but also acceptable to the native speaker. By contrast, no consideration is given to the implications of the fact that once inside their 'international' universities, students will communicate primarily in non-native lingua franca English groups using interactive pragmatic strategies that differ from those of native English academics (see below; and Björkman 2010 and this volume).

In other words, while many universities claim to be deeply international they are in essence deeply national at the linguistic level. And given that language is such a key component of academic life, their claim to internationalism rings somewhat hollow. The attachment to native English that still pervades global academic life is at odds with the current reality of English in which "[s]tatistically, native speakers are in a minority for [English] language use, and thus for language change, for language maintenance, and for the ideologies and beliefs associated with the language" (Brumfit 2001:116). For while an international perspective implies, English-wise, a language that is "bound up with transcultural flows, a language of imagined communities and refashioning identities" (Pennycook 2007:6), the focus in university settings, and particularly in their higher-stakes activities, remains firmly rooted in a bounded, national, monolinguacultural view of English. A genuinely international academic approach would mean accommodating (to) the diverse multilingual and multicultural populations that inhabit English-medium universities instead of expecting these populations themselves to accommodate (to) a narrow assimilationist model of English.

ELF research has already provided empirical evidence of what such an approach might involve, and has demonstrated that "we need a new kind of interactive pragmatics approach, involving the revision of key concepts and tenets that may have guided English language research practices in the past" (House 2009:141). In the following section, we will explore the key findings of ELF research before going on to consider its relevance for the international university.

\section{Research findings on English as a Lingua Franca}

\subsection{Defining ELF}

I begin by explaining precisely what I mean by ELF in order to clarify two key points that have crucial implications for academic settings: firstly, that ELF is not a deficient and failed attempt at native English, and secondly, that native English speakers are not excluded from mainstream definitions of ELF.

A useful basic definition is provided on the website of the Vienna-Oxford International Corpus of English (henceforth VOICE): ELF is "an additionally acquired language system which serves as a common means of communication for speakers of different first languages". Importantly, according to this definition, while native English speakers are not excluded from ELF, they are assumed to be using it - like non-native speakers - as "an additionally acquired language system". That is, ELF is not the same as their native English, and thus they too will need to acquire it in order to communicate successfully in ELF settings, rather than assuming their traditional role as norm providers. This is in contradistinction to another definition of ELF that is sometimes quoted, in which ELF is described as "a 'contact language' between persons 
who share neither a common native tongue nor a common (national) culture and for whom English is the chosen foreign language of communication" (Firth, 1996:240; emphasis in original). According to this interpretation, which is not shared by the majority of ELF researchers, native English speakers are seen as excluded from ELF communication. Moreover, Firth's interest in his 1996 article was in demonstrating how English may be used successfully in lingua franca communication, often by speakers with low proficiency levels, despite "anomalies and infelicities" as "recognized by native-speaker assessments" (p.239). In other words, he was describing deficient 'foreigner' English by comparison with a native English yardstick, rather than considering ELF as a kind of English in its own right, and whose speakers are often highly skilled and proficient (although in his recent writings, Firth's approach has altered somewhat in this latter respect, if not in terms of the 'excluded native speaker': see below, and Firth 2009a, 2009b).

For most ELF researchers, then, ELF and English as a Foreign Language (EFL) are two very different phenomena, which can be summed up as follows:

- ELF belongs to the global Englishes paradigm in which all Englishes are seen as sui generis rather than as attempts to approximate a native speaker version, whereas EFL belongs to the modern foreign languages paradigm, according to which the learning of English is no different from the learning of any other foreign language, with the goal of learning being to approximate the native speaker of the language as closely as possible.

- ELF therefore takes a difference perspective as contrasted with the deficit perspective of EFL. That is, differences from native English may be seen as legitimate variation according to ELF, but always as errors according to EFL. This is not to claim that ELF speakers are by definition proficient: some are still learners or have ceased learning before becoming proficient, in which case they will make errors. The crucial point is that there is a sociolinguistic distinction between ELF learners' errors and the innovations of proficient ELF users, even though the two sometimes result in the same forms.

- ELF's metaphors are of language contact and evolution, whereas EFL's metaphors are of interference and fossilization

- ELF sees code-mixing and code-switching as bilinguals' pragmatic strategies, while EFL sees them as evidence of gaps in knowledge (see Jenkins, 2006 for further discussion of the ELF-EFL distinction). From an ELF perspective, then, non-native English speakers are by no means the 'failed native speakers' of EFL. On the contrary, proficient ELF speakers emerge from the research as skilled communicators. They innovate in English making full use of their multilingual resources to create their own preferred forms. They code-switch as a means of promoting solidarity with their interloctuors and projecting their cultural identities. They make skilled and extensive use of the accommodation strategy of convergence for both affective reasons and to ensure comprehensibility. And in all of this, they prioritise communicative effectiveness over narrow predetermined notions of 'correctness'. In other words, their use of English is fluid and flexible, responding adeptly to the nature of the particular communicative context in ways that native English speakers, with their stronger attachment to native English norms, tend to find more challenging - points to which we will later return.

\subsection{Describing and analysing ELF communication}


We will now consider some of the empirical evidence on which these observations are based by exploring a number of the characteristics of ELF that have been identified in empirical research. Most of the findings presented here come from research that was carried out in academic settings, both informal and formal, thus emphasising their relevance for the international university.

So far, ELF research has focused chiefly on the spoken medium, and it is to this that we turn first, while possible implications for academic writing will be considered in Section 3. Whereas earlier ELF research focused mainly on surface linguistic features, more recent ELF research has shifted its attention to the pragmatic skills and strategies that underly these features. Having said that, the critical role of accommodation, which is emerging as possibly the single most important pragmatic skill in ELF communication, was identified even in the earliest research into ELF phonology (see Jenkins 2000, Cogo 2009). And although the "fascination with lists" and "feature spotting" (Seidlhofer 2008) that characterised the early descriptive work has given way to the desire "to achieve a better understanding of how these observed forms function in the communicative process" (ibid.), the forms themselves continue to serve at least two important, if obvious, purposes. Firstly, they provide the primary and most often the sole empirical evidence for the study of the pragmatics of ELF.

Secondly, despite some rather simplistic objections that ignore the relatively small size of ELF corpora, the possible effects of the 'observer's paradox' (Labov, 1972), and the fact that a statistically non-significant number of tokens may nevertheless indicate a change in progress (see, e.g., Crystal's comments on VOICE, in Stotesbury 2009), the empirically proven existence of these features in the speech of skilled ELF communicators enables ELF researchers to counter any claim that ELF is merely a deficient form of native English.

Turning first to the linguistic-based research, the following examples provide a taste of the kinds of features that have been identified as potential ELF features in the sense that they are used systematically and frequently, and found to be communicatively effective (possibly more so than the native English 'equivalent'). Starting with the phonological/phonetic research (see Jenkins, 2000), ELF speakers from a wide range of first languages regularly substitute voiceless and voiced 'th' with respectively $/ \mathrm{t} /$ and $/ \mathrm{d} /$ or $/ \mathrm{s} /$ and $/ \mathrm{z} /$. And they either vocalise dark ' $\mathrm{l}$ ' so that the ' $\mathrm{l}$ ' in 'bill' is pronounced as a ' $w$ ' (hence, 'biw'), or substitute it with clear ' 1 ' as it would be produced in the native English word 'lid'. They also tend to use word stress in ways that differ from native English, often placing the stress on the phonetically longest syllable in a word, e.g. on '-ate' in words such as 'educate' and on '-ise' in words such as 'supervise', leading Peng and Ann (2000) to hypothesize that an international wordstress rule may be emerging. ELF speakers also tend to avoid weak forms, using the full vowel sound rather than schwa in words such as 'but', 'for', 'them' and the like. Finally, the majority of ELF speakers use syllable-timed English rather than the non-syllable-timed English of most native varieties. In none of these features have the phonological/phonetic adjustments been found in the research to cause intelligibility problems, except in very isolated instances. Rather, it seems that native English pronunciation is more likely to cause communication problems in ELF settings, which may help account for some of the comments reported in section 4 below.

The same is true of lexicogrammatical and morphological features of ELF. At the lexical and morphological level, the empirical data reveals that ELF speakers create new words and collocations such as 'space time' and 'severe criminals' (VOICE); that their preferred meaning of so-called 'false friends' may be different from the preferred meaning in native English (e.g. 'actually' meaning 'currently' rather than 'in fact'), 
leading Hülmbauer (2007) to suggest that they would more appropriately be called 'true friends; and that they make novel use of morphemes such as 'boringdom', 'discriminization', 'forsify', 'levelize' and so on (see Björkman, 2008).

One frequent lexicogrammatical finding is that ELF speakers tend to change uncountable nouns into countable ones, such as 'informations', 'softwares', 'fundings', 'evidences', 'feedbacks'. Another is their use of an all-purpose question tag such as 'isn't it?' or 'no?'. A third is the use of one or other of 'who' and 'which'. For example, 'a paper who will be published', and 'it's the content who is important' (author's field notes). And perhaps the most frequently reported feature is zero marking of $3^{\text {rd }}$ person singular $-\mathrm{s}$ in the present tense. Interestingly, Dewey (2007) provides evidence demonstrating conclusively that the 'omission' of $3^{\text {rd }}$ person $-\mathrm{s}$ cannot be attributed to lack of competence. For in his data, when a native English lecturer joins the ELF student group, the students replace the 'missing' $-\mathrm{s}$. In other words, their communicative preference among themselves is for zero marking, but knowing that it is stigmatized by native English speakers, they may choose not to use this form in native/non-native interaction, particularly where the native speaker is in a more powerful position.

Another interesting factor, as Seidlhofer (2010) points out, is that many of the features being described as potential ELF forms involve regularisation processes of a kind similar to those that occur in native English. In other words, they involve changes such as redundancy reduction (as, for example, in the case of the lexicogrammatical features described in the previous paragraph) towards which the virtual English language is already predisposed. The difference is that because ELF is a situation of accelerated language contact, it is leading to accelerated language change and, in many respects, is simply speeding up regularisation processes that are already underway albeit more slowly in native English. Inevitably it is only possible for me to provide a snapshot of the vast amount of description of ELF available, but for many more examples, see in particular the VOICE corpus (which is available via the VOICE website free of charge) as well as the analysis in Breiteneder, 2009; Dewey, 2007; Erling and Bartlett, 2006; Hülmbauer, 2009, among many others.

Turning to data collected specifically in formal academic English settings, the ELFA corpus (English as a Lingua Franca in Academic Settings), although not yet available on-line has provided plentiful data from which its own researchers have been able to draw conclusions. For example, Mauranen (2009) explores the ways in which chunking operates in academic ELF as speakers employ chunks to manage their interactions and co-construct successful discourse. She analyses their interactive use of chunks ranging from short, fixed expressions to longer variable units, and finds the longer, more variable patterns to be more amenable to on-line innovation that deviates from native English convention, for example, "in/on my point of view", and "I'm not very sure". Mauranen notes that the speakers' non-standard expressions are neither random nor idiosyncratic, but rather, are indicative of the emergence of new ELF patterns, thus demonstrating ELF users' creativity.

Ranta (2006) similarly draws on the ELFA corpus to provide and analyse examples of the extended use of the progressive aspect by ELF speakers during academic presentations and seminars, in linguistic contexts where native English speakers would use the simple form. One such context involves stative verbs: "properties and relation are belonging to the same ontological or general category". A second involves habitual activity: "communication is so all embracive a concept, like are that we are breathing". And a third relates to points in past time: "This comes to the point I've been just mentioning before, it can lead to a clash of civilisation'. Ranta 
concludes that the participants in these ELFA interactions are assigning the progressive an extra function by comparison with native English use, because of their realization of its communicative value. That is, the -ing ending gives verbs more prominence in speakers' utterances and therefore draws their interlocutors' attention and ensures greater explicitness and clarity. To put it another way, these ELFA speakers are making an innovative use of a resource provided by the language for their own purposes - for an 'attention-catching' function.

The same phenomenon is found in the use of the expression 'more or less', which is apparently one of the most frequent markers of vagueness in academic ELF. In her analysis of the ways it is used in ELF academic discourse, Metsä-Ketelä (2006) finds that it is used a lot more than in native English academic discourse. She identifies three main functions of the expression in ELFA: minimising, comparing similarities, and approximating quantities. Even more significantly, by comparing her ELFA data with a corpus of native academic English, she finds that the minimising function of 'more or less' is restricted entirely to ELFA discourse, and that it is used particularly in question and answer situations such as research seminars and doctoral defences, where a researcher presents a study and then takes part in critical discussion of his or her work. For example:

We don't know exactly the evolution, we just have hypothesis, and er that is a big problem, how to assess a matter against another when you don't know anything for sure. Everything in this evolution is er more or less hypothesis. You can't make some measurements on the evolution.

Similarly:

Do you think this more or less bureaucratic difference makes the situation so different that Lithuania doesn't have the problem with the minority, while the other countries they do have?

Metsä-Ketelä argues on the basis of her analysis that while this minimising use of 'more or less' diverges from native English use of the expression, it causes no confusion in the interaction and supports the view that ELF speakers devise innovative ways of using the language and negotiating new meanings for old words.

These three ELF features, the innovative use of chunking, the extension of the progressive and the minimising function of 'more or less', all drawn from relatively formal ELFA settings, lead us neatly into the pragmatics of ELF, given that the use of these features was so clearly motivated by their respective speakers' awareness of their potential to fulfill particular communicative functions in the various interactions. As I pointed out earlier, the focus in ELF research has turned over the past few years from linguistic description to more pragmatic concerns and the overarching aims of discovering why certain forms are preferred over other forms, and the roles these forms play in interlinguacultural communication. And we turn now to explore these concerns in more informal academic settings.

Two groups of pragmatic processes have received particular attention, namely accommodation and code-switching (see e.g. Cogo 2007, 2009; Klimpfinger, 2009), although Cogo (2009), rightly in my view, treats code-switching as an accommodation strategy. In her 2007 study of an ELF community of practice (a group of university language teachers), she identifies both code-switching and repetition as strategies that are used to accommodate linguacultural diversity. In the following extract (2007:160), she demonstrates how speakers use repetition to align themselves with their interlocutors regardless of whether the repeated item would be considered nonstandard by comparison with native English: 
Chako (L1 Japanese): my [specific interest in point

Sila (L1 Mandarin): [yeah

Chako:

when did language I mean because of [revolution

Sila:

Chako:

did language change?

Sila:

Chako:

yeah [it's it changed

Sila:

[specifically intentionally

because of revolution but it also changed from the

beginning of the twentieth ce[ntury

Chako:

[yeah

Sila:

Chako:

[mhm mhm

Cogo argues that in repeating Chako's phrase "because of revolution" with zero article, Sila is accommodating from a grammatical perspective rather than simply omitting the article herself, since after this point, Sila tends to use the definite article, and also does so in other conversations. Cogo considers that Sila's convergence on Chako's utterance is motivated not only by the demands of communicative efficiency but also by a desire for alignment. That is, her repetition displays her attentiveness to her interlocutor's words and confirms them, whereas introducing the definite article into her repetition would have signalled lack of alignment and, probably, the desire to perform a repair.

Turning to code-switching, Cogo $(2007,2009)$ demonstrates how ELF speakers draw on their multilingual resources by switching into their own first languages as well as into the languages of their interlocutors, and even into languages that are not the mother tongue of any participant in the interaction. Code-switching, she points out, is an additional tool that multilingual speakers have at their disposal, enabling them to achieve various conversational goals in communication with each other. These include signalling solidarity and membership of the same multilingual (ELF) community, projecting their social and cultural identities, and providing nuances of expression that would be unavailable in the English language. Klimpfinger (2009), using data from VOICE, demonstrates likewise how ELF speakers code-switch to signal cultural identity, as well as for other functions such as specifying an addressee and introducing another idea into the conversation. Although Cogo and Klimpfinger also find occasional evidence of code-switching used to fill gaps in ELF speakers' linguistic knowledge, this is a minor function as contrasted with its far more prominent role in meaning making, a role in which it provides a rich resource to skilled multilingual speakers, and one that is by definition unavailable to monolingual English speakers. And as Wright (2009:112-13) points out in this respect, if native English speakers "remain monolingual with all the lack of awareness of how their first language is being used in second-language settings, they will be poor, ineffectual communicators", a point to which we will return. For now, suffice it to say that the English that is still being promoted in international communication in general, and international universities in particular, is monolingual native English: an English whose speakers are largely unaware of the rich potential of ELF and ELFA as outlined above.

\subsection{The fluidity and flexibility of ELF}

To sum up so far, empirical ELF research has demonstrated that ELF involves both the frequent, systematic use of certain forms that are not found in native English, and that its speakers employ a range of pragmatic on-line processes in determining which forms 
to use in any given interaction. This leads to a dilemma. As Seidlhofer (2009:240) points out, on the one hand "codification is recognised as a crucial requirement ... in terms of actual descriptions of certain observed regularities". But on the other hand, "this does not deny the inherent fluidity of ELF", in that ELF studies have shown how

ELF users exploit the potential of the language, they are fully involved in the interactions, whether for work or play. They are focused on the purpose of talk and on their interlocutors as people ... absorbed in the ad hoc, situated negotiation of meaning [which is] a far cry from calling up elements of a foreign language as they were learnt at school and pressing them into service as 'correctly' as possible (2009:242).

Other scholars make similar points about the fluidity of ELF. Pennycook (2009:195), for example, explains how "ELF research ... seeks to show how English is always under negotiation" and that "the ELF focus is trying to address precisely the gap left by the holes in the WE [World Englishes] model: How to come to grips with a noncentrist understanding of English as an international language that is dependent neither on hegemonic versions of central English nor on nationally defined new Englishes, but rather attempts to account for the ever-changing negotiated spaces of current language use". Likewise, Canagarajah (2007:926) points out that "[be]cause of the diversity at the heart of this communicative medium, LFE [Lingua Franca English] is intersubjectively constructed in each specific context of interaction" and that "[ $t]$ he form of this English is negotiated by each set of speakers for their purposes".

Leading on from this, and from the discussion of ELF pragmatics in the previous section, it becomes clear that ELF cannot be considered a 'variety' in any traditional sense of the term. Even the early language-focused ELF research had observed how ELF varied according to both speakers' other languages/cultures and the effect of contextual factors on accommodative behaviour. And since then, the contextual element has taken centre stage in ELF research and its role found to be rather more important than originally anticipated, with proficient (and not merely nonproficient) ELF speakers shown to exhibit substantial linguistic variation in their online communications with each other to project cultural identity, promote solidarity, share humour and the like, rather than primarily to promote intelligibility between speakers from different first language groups (Jenkins, 2000) and/or interlocutors with different proficiency levels (Firth, 1996).

The dilemma, then, is this: if ELF cannot be considered a variety in the traditional sense (or even a number of varieties each grounded in its speakers' first languages - as is the case with World Englishes), how can we conceive it? Seidlhofer's answer is that what ELF demonstrates is the need for us to consider new ways of thinking about concepts such as language variety and speech community in line with the changes that globalisation has brought with it. As she points out (2009:238): the crucial terms 'community' and 'variety' are, by and large, still used in the same way as they were long before the days of mass international travel, let alone electronic communication

and she adds:

at a time of pervasive and widespread global communication, the old notion of community, based purely on frequent face-to-face contact among people living in close proximity to each other, clearly does not hold any more.

She goes on to argue that "[a] much more appropriate concept is that of [Wenger's] communities of practice characterised by 'mutual engagement' in shared practices, 
taking part in some jointly negotiated 'enterprise' and making use of members' 'shared repertoire'(ibid.), which would appear to be entirely in keeping with the way ELF operates (and see Seidlhofer, 2007; Seidlhofer, 2010 for further discussion of these points).

For English at least, then, the nation-state view of language varieties and speech communities no longer holds true for the majority of the language's users around the globe. An alternative view is needed to replace it: one that can take account of the ways in which the vast number of ELF users skilfully co-construct English for their own purposes, by treating the language as a shared communicative resource within which they have the freedom to accommodate to each other, code-switch, and create innovative forms that differ from the norms of native English and do not require sanctioning by native English speakers. Those who find the notion of ELF difficult to grasp seem to be unable to look beyond traditional orientations to language, and to assume that there can only be two possibilities: either a language has to be a relatively fixed variety that can be codified in grammars and dictionaries, or it is a case of 'anything goes'. But ELF is different. Taking us back to Pennycook's 'transcultural flows" (2007) and his view of English as involving "ever-changing negotiated spaces of current language use" (2009:195; and see above), Firth (2009a) points out that it is not that ELF is too variable to be a variety: rather, it is that variability is itself one of ELF's principal characteristics. This means that as far as intercultural communication is concerned, a skilled English user is no longer someone who has 'mastered' the forms of a particular native variety of English, but someone who has acquired the pragmatic skills needed to adapt their English use in line with the demands of the current lingua franca situation.

This of course includes the lingua franca situation that exists in the international university, each of which is, itself, a microcosm of the global ELF community or, more specifically, the global academic ELF community. As such, universities that regard themselves as international (i.e. most if not all English medium universities) would seem to be perfect settings in which to explore the implications of ELF for their language policies and practices, as the prelude to moving on from their outdated narrow attachment to one or other national variety of English in the direction of something more genuinely international, contextually appropriate, and therefore flexible. For, as Mauranen points out in a letter to the Times Higher Education Supplement (21 September, 2007):

International academic communities communicate in largely non-native groups. What counts is clarity, effectiveness and contextual appropriateness of communication. While high academic standards are vital, native-like English is not.

The indications so far are mixed. There is little sign that those who are responsible for university language policy are aware of developments in academic ELF. On the other hand, as we will see in Section 4, some non-native students are at least starting to appreciate their advantages as multilingual speakers in academic ELF communities. In this respect, Montgomery (2008:21-23) points out that "it is students' developing and changing sense of themselves as part of such an international community that is important in this discussion" rather than any claim that "a physical 'global community' exists as such independently of these perceptions". Erling makes a similar point in relation to the German participants in her study at the Freie Universität in Berlin who, she argues, "are adding other layers of identity related to their affinities with other places and communities" (2007:128). This is all reminiscent of the "imagined communities' of Benedict Anderson (2006) - not a defined physical space, but a 
psychological one, in this case a sense of bonds with other (academic) ELF speakers. But despite Montgomery's point, this psychological community seems to me to translate naturally into physical communities of practice in Seidlhofer's sense (see above) when academic ELF users find themselves together. It is as if the psychological link of the virtual ELF community predisposes speakers to establish physical ELF communities of practice when the opportunity arises. Although this remains a hunch for now, it is certainly supported by empirical evidence such as the interview data from international and continental European masters students reported in Jenkins (2007).

\section{Implications for written academic English}

Turning briefly to academic writing, while the situation is even more static here than in relation to speech, there have recently been a number of challenges to the academic written English status quo. For example, Hu, a Chinese scholar, criticises the fact that non-native English academics are obliged to have their English 'corrected' by native speakers before their articles are accepted for publication in international academic journals. She goes on to describe how for non-native contributors, it is "necessary (as is the case with the author of this article who, incidentally, has never set foot in an English-speaking country) to have her China English adapted to one of the two standard varieties [i.e. British or American English] by a member of the Inner Circle, in order to ensure its acceptance at an international level" (2004:32). This is a somewhat paradoxical state of affairs for any journal that considers itself to be 'international', but all the more so for one called English Today, whose subtitle is "The international review of the English language", and whose cover contains a picture of the world. For as Kachru points out, "[w]hile it is perfectly legitimate to make all writers aware of the rhetorical patterns preferred in Inner Circle English ... it is equally legitimate and desirable to make English educators aware of the different rhetorical conventions of world majority learners and users of English" (2009:125).

Seidlhofer (2004) goes further, in arguing that there seems to be no principled justification for the norms of written academic English throughout the world to be those of Britain and North America. She points out that the practice of subjecting nonnative academic English to correction in order that their writing conforms to native conventions allows journals produced in native English countries "to exert a gatekeeping function based not on academic expertise but purely on linguistic criteria whose relevance for international intelligibility has not actually been demonstrated" (2004:222), a point similar to that made by Mauranen in the letter quoted above. Indeed, Mauranen herself eschewed the traditional 'correction' procedure in two recent volumes that she co-edited. In the first, a special issue of Nordic Journal of English Studies (Mauranen and Metsä-Ketelä, 2006), the editors say this in their introduction:

This special issue ... is written in ELF. Although native speakers have not been excluded from the volume, they have not acted as the ultimate authorities of linguistic correctness or comprehensibility. Thus, the papers have not been 'checked by a native speaker' as the saying goes (p.6).

Similarly, in the later book that she co-edited (Mauranen and Ranta, 2009), Mauranen and her co-editor make the point even more strongly:

Some of the papers in this book have been written by native speakers of English, others not, but all have been written by expert users of English. No policy of having the L2 authors' texts checked by native 
speakers for linguistic correctness has been applied, because this was regarded as an irrelevant practice in a book presenting international scholarship. Whether English has been the first or an additional language to the writers, they have been addressing an international audience, not primarily ENL (English Native Language) communities. Their contributions thus reflect the kind of language use they discuss: effective English as an international lingua franca.

The fact is that all writing in international journals is, by definition, for an international rather than an ENL audience. And yet the practice of having non-native scholars' writing 'checked by a native speaker' continues unabashed to this day, alongside evidence that academics writing in non-centre contexts, and who may not follow the norms of native academic English, continue to be disadvantaged (see e.g. Flowerdew 2001, 2008; Lillis and Curry 2006).

It seems, then, that the time is well due for us to take a long hard look at what and who international universities, journals, conferences and the like are for, and as part of the process, to consider the implications for the kinds of English that are appropriate to the international enterprise. One person who has done so is Ammon. He argues that empirical ELF studies "should be used for encouraging the acceptance of non-native forms to a much greater extent than today, and to motivate editors and publishers to consider them accordingly" (2007:131). He even proposes changing the name of English for international academic use to "Globalish", arguing that "[ $t]$ his new name would raise awareness of a status and function fundamentally different from the English language, namely a lingua franca, whose norms are no longer under the control of native speakers of English" (2006:25). Such a radical move would, of course, have serious implications for native English academics, an issue to which we turn in the next section.

\section{Implications for native English academics}

The difficulty for many native English speakers, both academics and non-academics, as far as the globalisation of English is concerned, seems to be that they still regard themselves in some sense as 'owners' and 'custodians' of the language. For many, thus, the internationalisation of English simply means the distribution of national British and/or North American English varieties around the globe. Such native English speakers have yet to appreciate Widdowson's point that " $[\mathrm{t}]$ he very fact that English is an international language means that no nation can have custody over it. To grant such custody is necessarily to arrest its development and so undermine its international status" (1994:385).

The most recent and disturbing demonstration of native English speaker custodianship of English in international academic settings is the phenomenon of the so-called 'offshore university'. This kind of institution, a university that has been set up - usually in East Asia - as an offshore branch of a British or North American university, seems in reality to be little more than an academic themepark, an academic version of that other recent global English phenomenon, the 'English village' (see Seargeant, 2005 for a discussion of an English village in Japan). One such example among many is Nottingham University's Ningbo campus in China. This is how its website describes its mission:

The University of Nottinham Ningbo's mission statement is "Academic Excellence in the Service of Global Citizenship", and this 
means that the University of Nottingham Ningbo, China has committed itself to developing subjects that combine internationally ranked teaching and research excellence at the University of Nottingham UK with Chinese needs for internationalization and globalization. This allows Chinese students to enjoy a world-class international education without the major expense of studying abroad. All undergraduate and postgraduate programmes in Ningbo are conducted entirely in English with the same teaching and evaluation standards as at Nottingham UK. The University has the Centre for English Language Education (CELE) dedicated to teaching English For Academic Purposes.

(www.nottingham.edu.cn, accessed 15 January 2010; emphasis added). Typically, the fact that the university's teaching, testing and research is carried out in exactly the same way as it is at the 'parent' UK institution is seen in an entirely positive light, as also is the teaching of (presumably) British academic English in its Centre for English Language Education. So while the aims of 'global citizenship' and 'a world-class international education' are in themselves commendable, they are apparently to be achieved by local means; and not even local in the Chinese sense, but local to the geographically, culturally and linguistically distant UK. The rather odd implication of the 'offshore university' phenomenon is that universities outside the mother tongue English speaking countries are regarded by the latter as unable to achieve academic internationalisation for themselves, and in order to do so, need complete guidance from mother tongue English institutions. And while there is often local demand for such 'offshore' institutions to be established, this in itself does not make the phenomenon any more acceptable. Rather, it serves to demonstrate how deeply the influence of standard native English ideology continues to be felt around the world.

The influence of the native English speaker ideology inherent in these kinds of enterprises, and that continues to pervade much discussion of the language, as well as most teaching materials, tests and the like, appears to lead many non-native English speakers to share, or at least, to not question, the perception of native ownership of English (see Jenkins, 2007). As a result, both native and non-native English users alike consider that native speakers have an international advantage. Van Parijs, for example, argues that " $[\mathrm{t}]$ he adoption of the native language of some as everyone else's lingua franca unavoidably raises a problem of justice" which calls for the need to find "a way of implementing a fair compensation for the free riding of [English] lingua franca natives on everyone else's learning" (2007:73). From a similar perspective, Crystal relishes the fact that he is, he believes, "already in the fortunate position of being a fluent user of the language which is most in contention for this role [a common language]" and adds that he has "cause to reflect every day on the benefits of having it at my disposal" (2003:viii).

However, as is very clear from the earlier discussion above, ELF is not Crystal's, or any other native English speaker's, language. Even though the starting point for native English speakers is less onerous than that for non-native speakers, it is nevertheless an additional language for them too. And as Coleman (in press) points out: [ $\mathrm{t}$ ] here is some satisfaction in recognising that English native speakers, arrogantly occupying for so long a privileged position as their language went global ... will be obliged to master international English [i.e. ELF] too". It could also be argued that not studying a foreign language should not be seen as gaining a 'free ride', but as a 
disadvantage in respect of the cultural and cognitive advantages that result from second language learning and that are not available to monolingual speakers.

Coleman's previous comment may seem over-optimistic. Nevertheless, ELF research has already demonstrated that native English speakers, particularly the monolingual majority, are less effective than non-native speakers in international communication. Among the reasons that have been documented are that they are less likely to be able to code-switch, less good at making use of accommodation strategies, and less free and flexible in their use of English than non-native speakers, who "are not influenced by standardising forces to the same extent" (Hülmbauer 2007:9). Thus, as Phillipson points out, "in many international fora, competent speakers of English as a second language are more comprehensible than native speakers, because they can be better at adjusting their language for people from different cultural and linguistic backgrounds" (2003:167). And there are signs that this is beginning to be noticed. Coleman (ibid.) argues, in line with Phillipson's point, that problems of understanding in English medium universities "are most severe not between non-native speakers of different origins, but for L1 English students who have difficulty in comprehending non-native teachers, and non-native students comprehending their native-speaking fellow students". This point emerged clearly in a recent study (Peckham et al., in press) carried out as part of the LINEE (Languages in a Network of European Excellence) project. The young ELF speakers, all Erasmus students in Hungary, described their own English as effective and creative even if it was not 'correct' according to native norms; they talked of native English speakers' lack of multilingualism as a problem; and they pointed out that communication breakdowns were mainly caused by native English speakers. For example:

I see that if I'm in the middle of people that are not English and they're speaking English, and so there is no problem understanding them. Probably my obstacle was that to understand like really English people talking (Italian student).

\section{Conclusion}

A little over twenty years ago, writing in this very journal, Haberland made the following observation:

The number of people who speak and write academic English and who are not native speakers of some other kind of English at the same time is fairly big. It must be possible for those people to attempt a creation of a new norm, which would be different from US or British English to the degree that speakers of those dialects would have to learn it if they want to write it or speak it properly (1989:936).

It seems bizarre that over twenty years later, and despite the findings of ELF research, English language policies and practices around the world are still - probably even more widely than before - premised on the 'need' for all to use native academic English. On the more positive side, however, it is interesting to note that in the UK context at least, there is evidence that the attitudes of many international students shift during their sojourn in UK universities. Although many arrive hoping to acquire a more 'nativelike' model of English, they tend to revise this goal during their stay, as a result of both gaining extensive first-hand experience of ELF communication among their peer group, and discovering that the English spoken by the local native speakers does not conform to the standard model they had been taught (see e.g. Adolphs, 2005). 
As a result of such developments, and the spread of ELF use more generally, Coleman (2006:11), ever the optimist, sees a brighter future:

As ELF diverges further from standard varieties in the UK, the US, Ireland or Australia, these countries too could become diglossic, and native speaker English become a sociolinguistically marked variety, no longer automatically acceptable in international contexts. Then the predominance of international academics with a range of native tongues other than English may well diversify even academic discourse away from today's ubiquitously delocalized AngloAmerican standard. And the world may see the emergence of a more democratic model of English as a lingua franca".

If Coleman is right and this change materialises, it will benefit not only the students themselves, but also non-native English-speaking content lecturers in universities around the world, who are still themselves expected to speak 'native-like' English (See Björkman 2010). In the meantime, being more of a pessimist, I will continue to end my lecture on ELF to students on the presessional English for Academic Purposes course at my own UK university as follows:

Your lecturers will expect you to use nativelike English norms. But you can educate them about ELF and the fact that it is a contradiction for any university anywhere that considers itself international to insist on national English language norms.

\section{References}

Adolphs, Svenja, 2005/2009. "I don't think I should learn all this" - a longitudinal view of attitudes towards 'native speaker' English. In: Gnutzmann, C., Intemann, F. (Eds.) The Globalisation of English and the English Language Classroom. Tübingen, Gunter Narr, 119-132.

Ammon, Ulrich, 2006. Language planning for international scientific communication: an overview of questions and possible solutions. Current Issues in Language Planning 7 (1), 1-30.

Ammon, Ulrich, 2007. Global scientific communication: open questions and policy suggestions. In: Carli, A., Ammon, U. (Eds.), Linguistic inequality in scientific communication today. John Benjamins, Amsterdam/Philadelphia, pp. 123-133.

Anderson, Benedict, 2006. Imagined Communities. Verso, London.

Björkman, Beyza, 2008. "So where we are" Spoken lingua franca English at a technical university in Sweden. English Today 24 (2), 35-41.

Björkman, Beyza, 2010. Spoken lingua franca English at a Swedish university: an Investigation of form and communicative effectiveness. Unpublished $\mathrm{PhD}$ Dissertation, University of Stockholm.

Breiteneder, Angelika, 2009. English as a lingua franca in Europe: an empirical perspective. World Englishes 28 (2), 256-69.

Brumfit, Christopher, 2001. Individual Freedom in Language Teaching. Oxford University Press, Oxford.

Canagarajah, A. Suresh, 2007. Lingua Franca English, multilingual communities and Language acquisition. Modern Language Journal 91, Focus Issue, 923-939.

Cogo, Alessia, 2007. Intercultural Communication in English as a Lingua Franca: A Case Study. Unpublished PhD dissertation, King's College. London. 
Cogo, Alessia, 2009. Accommodating difference in ELF conversations: a study of Pragmatic strategies. In: Mauranen, A., Ranta, E. (Eds.), English as a Lingua Franca: Studies and Findings. Cambridge Scholars Publishing, Newcastle, 254270.

Coleman, Jim, 2006. English-medium teaching in European higher education. Language Teaching 39, 1-14.

Coleman, Jim, in press. Multilingualism in contexts: the relativity of time and space. In: Wiater, W. , Videscott, G. (Eds.) Migration and Mehrsprachigkeit. Peter Lang, Bern.

Crystal, David, 2003. English as a Global Language. Cambridge University Press, Cambridge.

Dewey, Martin, 2007. English as a Lingua Franca: An Empirical Study of Innovation in Lexis and Grammar. Unpublished PhD dissertation, King's College London.

ELFA (ELF in Academic Settings) website: www.eng.helsinki.fi/elfa/

Erling, Elizabeth, 2007. Local identities, global connections: affinities to English Among students at the Freie Universität Berlin. World Englishes 26 (2), 111 130.

Erling, Elizabeth, Bartlett, Tom, 2006. Making English their own: the use of ELF Among students of English at the FUB'. Nordic Journal of English Studies 5 (2), 9-40.

Firth, Alan, 1996. The discursive accomplishment of normality. On "lingua franca" English and conversational analysis. Journal of Pragmatics 26, 237-59.

Firth, Alan, 2009a. The lingua franca factor. Intercultural Pragmatics 6 (2), 147-70.

Firth, Alan, 2009b. Doing not being a foreign language learner: English as a lingua franca in the workplace and (some) implications for SLA. International Review of Applied Linguistics 47, 127-56.

Flowerdew, John, 2001. Attitudes of journal editors to non-native speaker contributions. TESOL Quarterly 35, 1, 121-150.

Flowerdew, John, 2008. Scholarly writers who use English as an additional language: what can Goffman's "Stigma" tell us? Journal of English for Academic Purposes 7, 77-86.

Graddol, David, 2006. English Next. British Council, London.

Haberland, Hartmut, 1989. Whose English, nobody's business. Journal of Pragmatics $13,927-38$.

Harris, Roy, 2007. Opinion. Times Higher Education Supplement, 30 March 2007, p. 12 .

House, Juliane, 2009. Introduction: The pragmatics of English as a Lingua Franca. International Pragmatics 6 (2), 14-45.

$\mathrm{Hu}$, Xiaoqiong, 2004. Why China English should stand alongside British, American, and the other 'world Englishes'. English Today 20 (2), 26-33.

Hülmbauer, Cornelia, 2007. The relationship between lexicogrammatical correctness and communicative effectiveness in English as a lingua franca. Vienna English Working Papers 16 (2), 3-35.

Hülmbauer, Cornelia, 2009. 'We don't take the right way. We just take the way that we think you will understand' - the shifting relationship between correctness and effectiveness in ELF. In: Mauranen, A., Ranta, E. (Eds.), English as a Lingua Franca: Studies and Findings. Cambridge Scholars Publishing, Newcastle, 323-47.

Jenkins, Jennifer, 2000. The Phonology of English as an International Language. 
Oxford: Oxford University Press.

Jenkins, Jennifer, 2006. Points of view and blind spots: ELF and SLA. International Journal of Applied Linguistics 16 (2), 137-162.

Jenkins, Jennifer, 2007. English as a Lingua Franca: Attitude and Identity. Oxford: Oxford University Press.

Kachru, Yamuna, 2009. Academic writing in world Englishes: the Asian context. In: Murata, K., Jenkins, J. (Eds.), Global Englishes in Asian Contexts. Palgrave, Houndmills, Basingstoke, pp.111-30.

Klimpfinger, Teresa, 2009. "She's mixing the two languages together" - forms and functions of code-switching in English as a Lingua Franca. In: Mauranen, A., Ranta, E. (Eds.), English as a Lingua Franca: Studies and Findings. Cambridge Scholars Publishing, Newcastle, pp. 348-371.

Labov, William, 1972. Sociolinguistic Patterns. University of Pennsylvania Press, Philadelphia.

Lillis, Teresa, Curry, Mary Jane, 2006. Professional academic writing in higher education: an academic literacies approach. Studies in Higher Education 23, 157-172.

Mauranen, Anna, 2009. Chunking in ELF: expressions for managing interaction. Intercultural Pragmatics 6 (2), 217-233.

Mauranen, Anna, Metsä-Ketelä, Maria (Eds.) 2006. Nordic Journal of English Studies 5 (2). Special Issue: English as a Lingua Franca.

Mauranen, Anna, Ranta, Elina (Eds.) 2009. English as a Lingua Franca: Studies and Findings. Cambridge Scholars Publishing, Newcastle.

Metsä-Ketelä, Maria, 2006. Words are more or less superfluous. Nordic Journal of English Studies 5 (2), 117-143.

Montgomery, Catherine, 2008. Global futures, global communities? The role of culture, language and communication in an internationalised university. In:

Haberland, H., Mortensen, J., Fabricius, A., Preisler, B., Risager, K. and Kjærbeck, S. (Eds.), Higher Education in the Global Village. Roskilde University. Roskilde, Denmark.

Moore, Julie, 2007. Common mistakes at IELTS Advanced ... and how to avoid them. Cambridge University Press, Cambridge.

Murata, Kumiko, Jenkins, Jennifer (Eds.) 2009. Global Englishes in Asian Contexts. Palgrave, Houndmills, Basingstoke.

Peckham, Don, Kalocsai, Karolina, Kovács, Emöke, Tamah, Sherman, in press. English and multilingualism, or English only in a multilingual Europe? In: Studer, P., Werlen, I. (Eds.), Linguistic Diversity in the European Union: First Findings of LINEE. Mouton de Gruyter, Berlin/ New York.

Peng, Long, Jean, Ann, 2000. Stress and duration in three varieties of English. World Englishes 20 (1), 1-27.

Pennycook, Alastair, 2007. Global Englishes and Transcultural Flows. Routledge, London.

Pennycook, Alastair, 2009. Plurilithic Englishes: towards a 3D model. In: Murata, K., Jenkins, J. (Eds.), Global Englishes in Asian Contexts. Palgrave, Houndmills, Basingstoke, pp. 194-207.

Phillipson, Robert, 2003. English-Only Europe? Challenging Language Policy. London: Routledge.

Ranta, Elina, 2006. The 'attractive' progressive - why use the -ing form in English as a Lingua Franca? Nordic Journal of English Studies 5 (2), 95-116.

Seargeant, Philip, 2005. 'More English than England itself': the simulation of 
Authenticity in foreign language practice in Japan. International Journal of Applied Linguistics 15 (3), 326-345.

Seidlhofer, Barbara, 2004. Research perspectives on teaching English as a Lingua Franca. Annual Review of Applied Linguistics 24: 209-239.

Seidlhofer, Barbara, 2007. English as a lingua franca and communities of practice. In S. Volk-Birke and J. Lippert (Eds.) 2007 Anglistentag 2006 Halle Proceedings, Trier: Wissenschaftlicher Verlag: 307-18.

Seidlhofer, Barbara, 2008. ELF findings: form and function. Keynote talk given at the $1^{\text {st }}$ International Conference of English as a Lingua Franca, Helsinki, March 2008.

Seidlhofer, Barbara, 2009. Common ground and different realities: world Englishes And English as a lingua franca. World Englishes 28 (2), 236-245.

Seidlhofer, Barbara, 2010. Understanding English as a Lingua Franca. Oxford: Oxford University Press.

Stotesbury, John, 2009. An interview with David Crystal. The European English Messenger 18 (2), 51-58.

Van Parijs, Philippe, 2007. Tackling the Anglophones' free ride: fair linguistic cooperation with a global lingua franca. In: Carli, A., Ammon, U. (Eds.), Linguistic Inequality in Scientific Communication Today. AILA Review 20, John Benjamins, Amsterdam, 72-86.

VOICE (Vienna-Oxford International Corpus of English) website: www.univie.ac.at/voice

Widdowson, Henry, 1994. The ownership of English. TESOL Quarterly 28 (2), 37789.

Widdowson, Henry, 1997. EIL, ESL, EFL: global issues and local interests. World Englishes 16 (1), 135-146.

Wright, Sue, 2009. The elephant in the room: language issues in the European Union. European Journal of Language Policy 1 (2), 93-120.

Jennifer Jenkins is Professor of Global Englishes at the University of Southampton, where she teaches undergraduate/postgraduate courses and supervises doctoral research in global Englishes. She has researched ELF since 1989 and published copious journal articles and chapters on the subject, along with two monographs, The Phonology of English as an International Language (OUP, 2000) and English as a Lingua Franca: Attitude and Identity (OUP, 2007), as well as a university course book, World Englishes (Routledge, $2^{\text {nd }}$ ed. 2009), and two co-edited volumes: Reconfiguring Europe (Equinox, 2006, with Constant Leung) and Global Englishes in Asian Contexts (Palgrave, 2009, with Kumiko Murata). 